\title{
CONSIDERAÇÕES SOBRE A SUBDIVISÃO ESTRATIGRÁFICA DA FORMAC̣ÃO SANTANA, CRETÁCEO DO NORDESTE DO BRASIL
}

\author{
MURILO RODOLFO DE LIMA*
}

\begin{abstract}
By present consensus, three distinct members can be recognized in the sedimentary sequence of the Santana Formation (Araripe Group), Cretaceous of northeastern Brazil named, respectively, Crato, Ipubi and Romualdo. This subdivision was presented by BEURLEN (1971, p. 415), based on environmental differences related to the proposed members. In the present study, the viability of this subdivision is examined. Analysis of the information, now available, permits the conclusion that only the Crato Member should be mantained in reality. The other proposed subdivisions should be abandoned or redefined, since their representative sequences do not truly reflect distinct phases in the sedimentary deposition of the Santana Formation.
\end{abstract}

INTRODUÇÃo A Bacia do Araripe, cuja sequiência estratigráfica inclui a Formação Santana, corresponde a um conjunto litológico complexo que ocorre no interior do Nordeste do Brasil, mais precisamente na região limítrofe dos Estados do Ceará, Pernambuco e Piauí.

Foi Small (1913) quem pela primeira vez a estudou sob o ponto de vista estratigráfico, apesar de seus fósseis serem conhecidos desde o século passado. Na ocasião, o autor efetuou uma subdivisão preliminar da sequiência, reconhecendo 3 seções distintas: um arenito inferior portando um conglomerado basal, uma seção média essencialmente calcífera (designada "Calcários de Sant'Anna") e uma superior, novamente arenítica. Posteriormente, Moraes (1928, p. 62-65) confirmou as observações de Small, sem contudo refinar os conhecimentos estratigráficos da área, que permaneceram durante longo tempo em nível estritamente superficial. Nos últimos anos, contudo, a região tem suscitado um grande interesse dos estudiosos, em função de suas potencialidades no setor econômico. Salientam-se no aśpecto estratigráfico, as contribuições de Beurlen (1962, 1963, 1971), Anjos (1964), Braun (1966), Silva Santos e Valença (1968) e Moraes (1976), todas fornecendo novos subsídios para o conhecimento mais pormenorizado da coluna.

No estágio atual de conhecimento, as opiniões são unânimes no que se refere à presença de sedimentos paleozóicos na bacia, correspondendo ao "Conglomerado Basal" de Small (op. cit.). Todos concordam também com a fase mais importante da sua história deposicional corresponde ao Cretáceo Inferior, estando esta sequiência, representada por 3 unidades estratigráficas distintas, depositada em discordância erosiva sobre a anterior. No aspecto concernente às designações formais das unidades que compõem a seqüência estratigráfica, bem como às suas subdivisões, as opiniões con- tudo continuam divergentes, como pode ser verificado na Fig. 1, qứ reúne as várias proposições efetuadas. Com relação à Formação Santana, o consenso atual (Beurlen, 1971, p. 415) é de que esta unidade pode ser subdividida em 3 membros, respectivamente denominados Crato, Ipubi e Romualdo. O que se pretende neste trabalho é verificar a viabilidade desta subdivisão, com base em extensivo trabalho de campo e em um zonamento bioestratigráfico global desta unidade sedimentar, visando esclarecer as relações de dependência entre as mudanças litológicas nos limites dos membros propostos, com variações ambientais refletidas nas modificações das associações de fósseis.

A FORMAÇÃO SANTANA A Formação Santana é caracterizada por uma grande diversidade litológica, verificável ao longo de sua espessura, cujo limite máximo é de aproximadamente $200 \mathrm{~m}$. Dificilmente se encontra toda a seção exposta em um só local. Os flancos N-NE da bacia são, entre todos, os que exibem melhor esta diversidade, devido às características do relevo do embasamento. No flanco S, a Formação Santana também é espessa. Aparecem, contudo, em afloramentos apenas os níveis mais superiores da unidade. Nos flancos SE, SW, W e NW a sequiência litológica torna-se bastante reduzida. Faltam quase que completamente os sedimentos representativos da base da seqüência, sendo visíveis apenas os níveis mais superiores.

Com relação aos contatos, tanto o inferior quanto o superior são considerados transicionais no sentido litológico, pela maioria dos estudiosos. O contato inferior, segundo descrição original de Small (1913, seção n. ${ }^{\circ} 8$ ), situa-se no nível em que arenitos finos ou siltitos, de vermelhos ou variegados, passam a uma coloração cinza uniforme. Verifica-se aí, contudo, uma provável discordância no sentido paleontológico, pois 


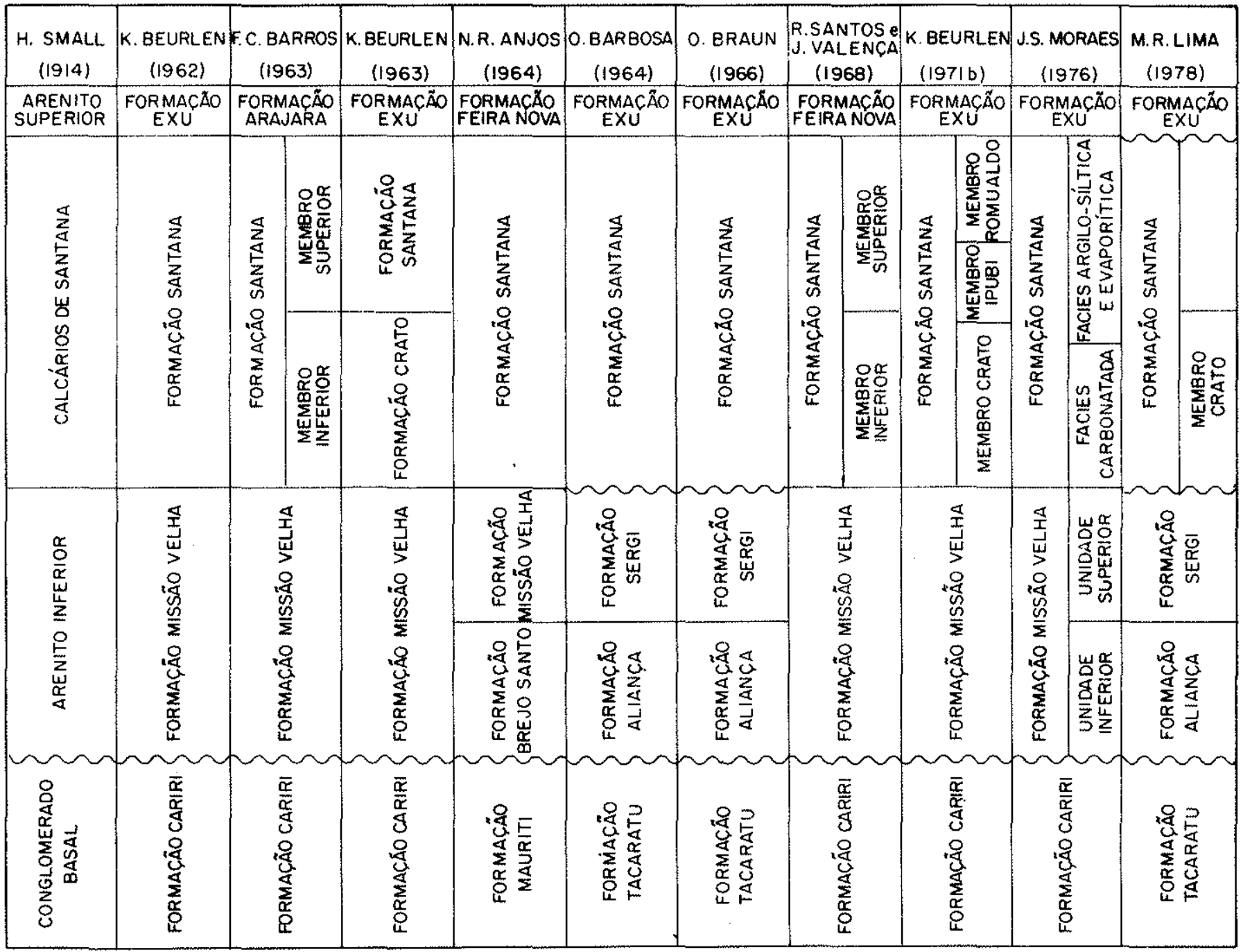

Figura 1 - Quadro comparativo das diversas subdivisões estratigráficas propostas para a sequiência sedimentar da Bacia do Araripe (adaptado de Veiga, 1966)

os fósseis presentes nos níveis próximos ao contato nas duas unidades (Missão Velha e Santana) fornecem idades distintas para as camadas que os portam (Lima, $1978 \mathrm{a}$, p. 18). Quanto ao limite superior, na verdade é também discordante, tendo sido detectada no flanco SW da bacia (região de Serra Branca) uma visível paraconformidade nos niveis síltico-argilosos que constituem a transição Santana-Exu. (Lima, 1978b)

Perfil geral Ao todo, foram estudados 12 perfis, distribuídos de modo a cobrir, da melhor forma possivel, as áreas de ocorrência da Formação Santana nos flancos da chapada. Alguns desses perfis foram obtidos diretamente em trabalhos de campo, realizados ao longo de riachos que descem as escarpas da serra. Outros foram obtidos a partir da descrição de testemunhos de sondagem, em perfurações efetuadas por instituições ou companhias de pesquisa atuantes na região. Em ambos os casos, torna-se dificil o estabelecimento de um posicionamento seguro dos mesmos.
Assim, considerando-se os perfis obtidos em afloramentos, faltam em geral referências geográficas que possibilitem a localização precisa dos pontos de início e final dos mesmos. No caso de testemunhos de sondagem, as cotas dos locais de perfurações são relativas, já que a altimetria dos pontos de referência normalmente utilizados não é absolutamente confiável. Para solucionar o problema, os perfis foram calibrados através de dois planos data. O primeiro deles, válido para os perfis de $n .{ }^{\circ}{ }^{\circ} 1,2,3,4,5,9,11$ e 12 (veja Fig. 2), que atravessam a metade inferior da unidade, foi arbitrado no topo da última ocorrência de calcário laminado. $\mathrm{O}$ segundo, válido para os perfis de $n .^{\circ} 6,7,8$ e 10 que atravessam a metade superior da formação, foi arbitrado no topo da camada evaporítica. Os perfis de $n^{\text {os }} 5$ e 9 , que são os mais completos, registram simultaneamente a posição dos dois data utilizados, permitindo assim a correlação operacional de todas as seções. Do estudo geral das seções referidas, foi 


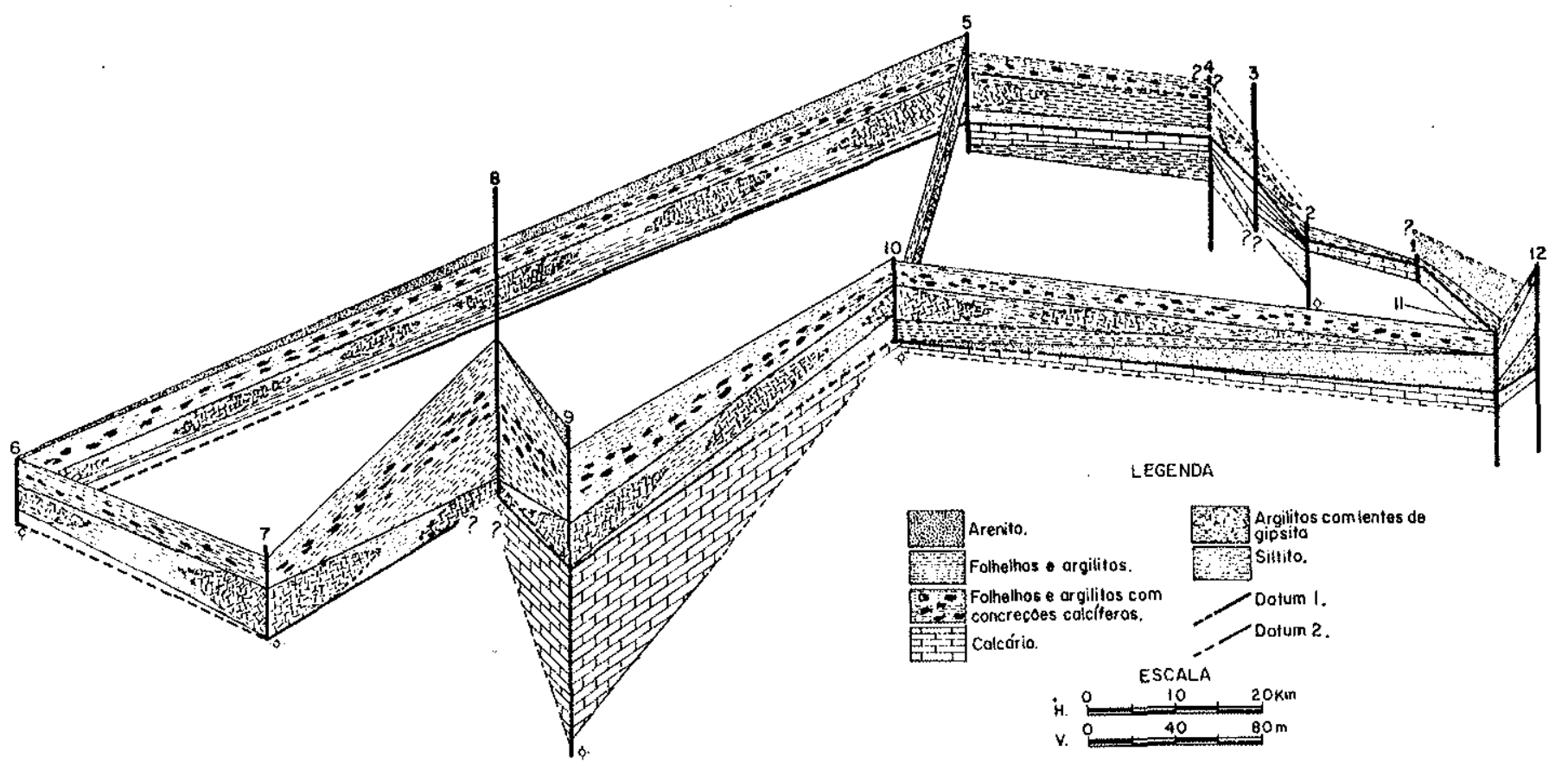

Figura 2 - Correlação litoestratigráfica dos perfís estudados com base em data pré-arbitrados

possivel a elaboração de um perfil composto, inferido a partir de espessuras máximas das litologias encontradas nos locais estudados.

A formação inicia-se (veja Fig. 3) por uma sequiência de arenitos e siltitos, cuja coloração varia do cinza ao amarelo, visíveis no perfil $n .{ }^{\circ} 3$. Gradualmente passam a predominar clásticos mais finos, que mais acima constituem uma sequiência típica de folhelhos e argilitos cinzentos, contendo abundantes placas de mica. Intercalados nestes argilitos e folhelhos, ocorrem ainda alguns níveis areníticos esporádicos. Aos poucos, a sequiencia sedimentar assume um caráter cíclico, com deposição alternada de folhelhos e arenitos, idênticos aos já mencionados, com uma coloracão cinza. Os folhelhos, mais escuros, apresentam com frequiencia laminação convoluta e cristais de pirita. Os arenitos, por sua vez, são sempre muito feldspáticos, exibindo estratificação cruzada e marcas de sobrecarga. Mais acima os níveis areníticos tendem a desaparecer, mantendo-se apenas os folhelhos, que se tornam ainda mais escuros. Começam a aparecer então níveis de calcário creme, laminado, criptocristalino. Novamente um caráter cíclico tende a se instalar, com alternância de folhelhos (agora claramente betuminosos) e calcários. Tais ciclos tornam-se mais espessos, de maneira progressiva, aparecendo a certa altura em niveis de até $8 \mathrm{~m}$ de espessura. Após a ocorrência deste nivel, repete-se a sequiência, com deposição de folhelhos e siltitos, folhelhos e arenitos, arenitos puros. Voltam então a se depositar siltitos, intercalações de siltitos, folhelhos, e um segundo nível cal- cário com as mesmas características do anterior, com espessura de até $3 \mathrm{~m}$.

Após a ocorrência deste segundo banco, as litologias assumem uma maior variação faciológica. Depositam-se simultaneamente arenitos em espessos pacotes (perfil n. ${ }^{\circ} 12$ ), margas e folhelhos cinza escuro, não betuminosos. Aparecem em alguns locais, principalmente nos niveis de margas e folhelhos, algumas lentes de gipsita. Acima, encontra-se uma camada constituída de argilitos cinza escuros, intercalados com lentes de gipsita. Localmente, estas lentes podem atingir uma extensão considerável e uma espessura de até $30 \mathrm{~m}$. Em alguns locais da bacia a camada está representada unicamente pelos argilitos, constituindo a gipsita apenas veios centimétricos ou cristais isolados.

Na capa da camada que contém as lentes de gip. sita, segue-se outra fase de grande variação faciológica, com deposição simultânea de arenitos finos intercalados com argilitos, folhelhos ou margas, todos de cor cinzenta. Mais acima, os argilitos passam novamente a constituir a única litologia em toda a bacia. São sempre de cor cinzenta, e caracteristicamente estes pelitos, localmente calcíferos, portam concreções calcárias de tamanho centimétrico a decimétrico de formato variável, freqüentemente fossiliferas. Na direção do topo da formação, as concreções tendem a desaparecer. Permanecem contudo os argilitos, que gradam depois para siltitos cinzentos e, finalmente, para arenitos. Estes marcam o início da Formação Exu, possuindo sempre em afloramentos uma cor amareloavermelhada. 


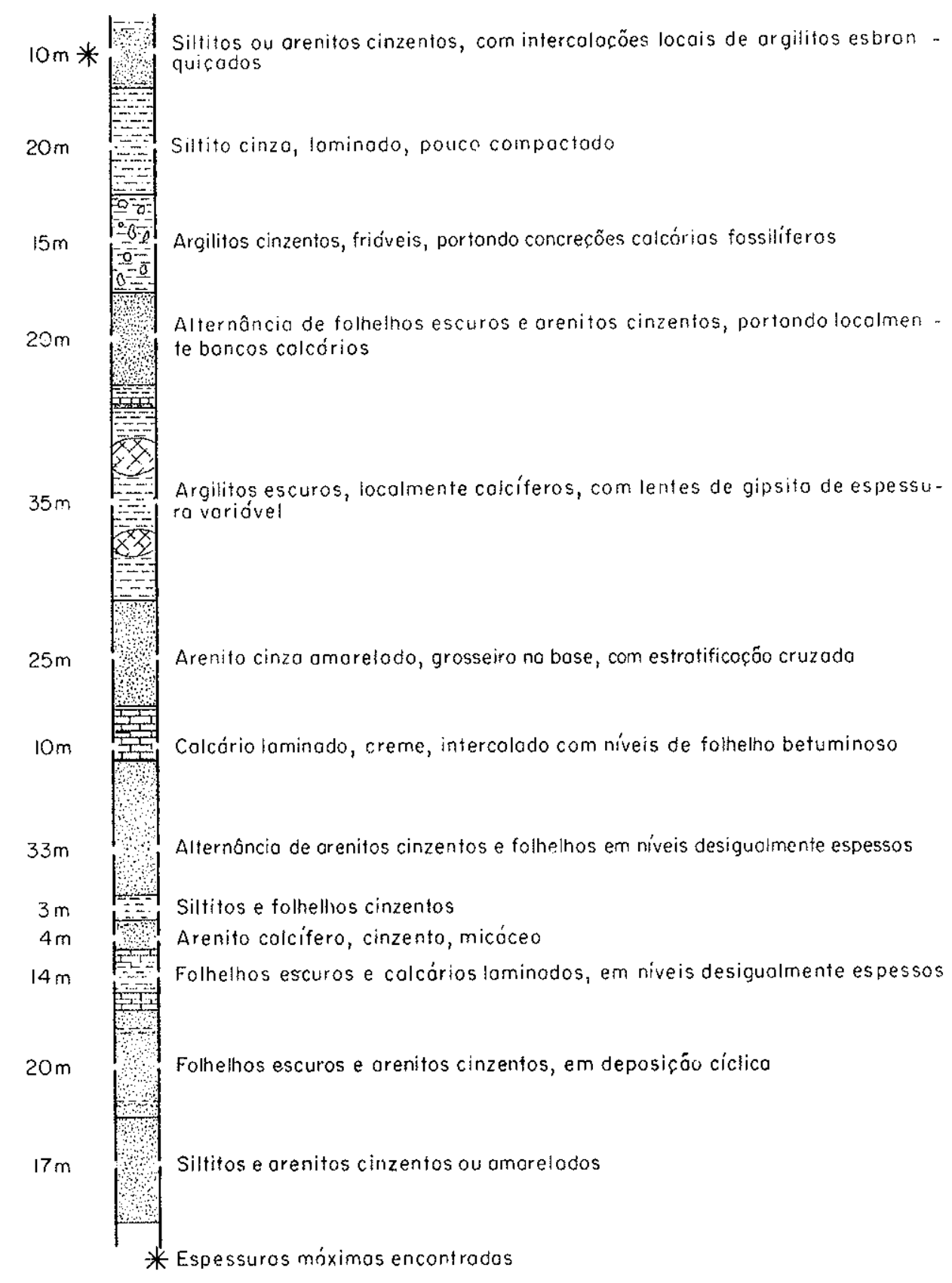

Figura 3 - Perfil composto inferencial da Formação Santana nos locais estudados

IMPLICACÕ̃ES LITOESTRATIGRÁFICAS DECORRENTES DO ZONEAMENTO BIOESTRATIGRÁFICO DA FORMAÇ̃O SANTANA - As associações de fósseis permitiram o estabelecimento de 4 zonas palinológicas na seção estudada (Lima, 1978a). A única discordância detectável é a que separa as Zonas 3 e 4 , sendo aqui interpretada como o limite entre as Formações Santana e Exu. Em consequiência, as Zonas 1, 2 e 3 pertencem efetivamente a uma mesma unidade estratigráfica (Formação Santana), enquanto a mais superior (4) corresponde a sedimentos da Formação Exu (Lima, 1978b).
Segundo Beurlen (1971b, p. 415), os Membros Crato, Ipubi e Romualdo refletem diretamente condições ecológicas reinantes na bacia. Correspondem a uma fase inicial não marinha (representada pelos sedimentos basais até os calcários laminados), seguida por uma fase marinha (representada pelos argilitos com lentes evaporíticas ou com concreções fossilíferas associadas) a qual se sobrepõem novamente sedimentos não marinhos do topo da formação. Evidentemente este critério não é formalmente válido para a proposição de membros, já que o Código de Nomenclatura Estratigráfica postula (Art. 4) a total indepen- 
dência das unidades litoestratigráficas em relação à história geológica inferível. Entretanto, concordamos com Beurlen (op. cit.) no sentido de que as unidades estratigráficas reais devem retratar fases distintas na história deposicional de uma bacia. Em consequiência, se os ambientes mencionados realmente se refletem nas litologias presentes, tal subdivisão poderia ser de grande conveniência para orientação dos trabalhos geológicos futuros na área em questão.

Como já foi visto, entretanto, a complexidade faciológica da Formação Santana é maior que a originalmente suposta. Apenas as litologias mais basais, correspondentes ao Membro Crato, são realmente tabulares, sendo sucedidas por fáceis sincrônicas de expressão mais local. Como não há discordância visivel, no sentido palinológico, entre as zonas mais basais, admitimos que o Membro Crato deve ser mantido sob este status, já que seus sedimentos representativos fazem parte do mesmo "ciclo" deposicional ao qual pertencem os demais membros. Consequientemente, estes estratos não devem ser considerados, segundo pensam alguns autores, como uma formação isolada. Cumpre ressaltar que tal conclusão está perfeitamente de acordo com a idéia inicial de Small (1913) que utilizou o termo Sant'Anna para designar uma seqüência predominantemente calcífera a qual pertencem, pela sua natureza, os calcários do Membro Crato. Quanto aos demais membros, devem ser, ao contrário, abandonados ou redefinidos, pelas razões a seguir expostas:

O Membro Ipubi corresponderia aos niveis evaporíticos associados aos argilitos, bem como os imediatamente superpostos, constituidos de folhelhos, argilitos e margas contendo concreções calcárias. Palinologicamente, contudo, pode-se provar que as concreções ocorrem em níveis marinhos e não marinhos, não havendo nenhuma diferença litológica observável na matriz que as contém. Na base desse membro, claramente superpostos aos níveis do Membro Crato, ocorrem sedimentos areníticos também não marinhos, visíveis na extremidade NE da bacia. Ocorre, portanto, uma sucessão de fáceis marinhas e não marinhas, distintas no sentido litológico, que não poderia ser englobada sob a denominação mencionada.

O Membro Romualdo corresponde por definição a sedimentos areníticos intercalados com finos níveis argilíticos, presentes na localidade do mesmo nome (perfil n." 4 da Fig. 2), representando o topo da formação. Inicialmente, deve ser observado que os sedimentos representativos deste membro são realmente não marinhos. Contudo, no sentido estratigráfico, eles ocorrem abaixo dos níveis de argilitos e margas com concreções fossiliferas, estando praticamente superpostos aos niveis evaporíticos. Em conseqüência, os estratos correspondentes ao membro superior da formação estariam na verdade intercalados ao membro médio, o que é totalmente inaceitável. A idéia mais plausivel é de que estes sedimentos representem, em verdade, mais uma fáceis de expressão local.

CONCLUSỚES Das observações acima expostas, as seguintes conclusões podem ser inferidas:

a) A Formação Santana representa efetivamente um conjunto sedimentar com caracteres litológicos e ambientais distintivos, dentro da sequiência que constitui o Grupo Araripe. Trata-se de uma sucessão litológica contínua, não havendo nenhuma discordância detectável durante a sua deposição, mesmo de caráter paleontológico. Em conseqüência, nada justifica a separação de alguns dos seus estratos na condição de uma outra unidade litoestratigráfica independente.

b) Os sedimentos basa is distinguem-se claramente do restante do conjunto que constitui a Formaçào Santana. São tabulares, de grande homogeneidade lateral e fácil reconhecimento. A sua designação como Membro Crato é pois altamente conveniente, devendo ser mantida.

c) Os demais membros descritos, correspondentes à parte média e superior da formação, devem, ao contrário do anterior, serem abandonados ou redefinidos, por não ser possível caracterizá-los adequadamente, em função da grande variação faciológica e relações de contato complexas.

Agradecimentos Esta publicação constitui parte de trabalho apresentado como Tese de Doutoramento perante o IG/USP, sendo parcialmente financiado pelo Conselho Nacional de Desenvolvimento Cientímfico e Tecnológico, Câmara de Pós-Graduação da Universidade Federal de Pernambuco e Instituto de Geociências da Universidade de São Paulo, aos quais consignamos o nosso agradecimento. Destacamos também a decisiva participação dos Profs. Drs. Benjamin Bley de Brito Neves (CT-UFPE), Thomas R. Fairchild (IG-USP) e Diógenes de Almeida Campos (DNPM) através de valiosas críticas e sugestões apresentadas. 


\section{BIBLIOGRAFIA}

ANJOS, N.F.R. dos - 1964 - Mise en valeur du Bassin du Jaguaribe. Études Générales de base (1962, 1964). Rev. Conv. ASMIC/SUDENE: 1-180.

BARBOSA, O. - 1964 - Relatório preliminar do "Projeto Cobre" - PROSPEC/SUDENE (inédito).

BARROS, F.C. - 1963 - Sobre a sistemática da Série Araripe. Rev. Eng. Min. Metal. 37 (218): 52.

BEURLEN, K. - 1962 - A Geologia da Chapada do Araripe. An. Acad. Bras. Ciênc. 34 (3): $365-370$.

BEURLEN, K. - 1963 - Geologia e Estratigrafia da Chapada do Araripe, XVII Cong. Bras. Geol. Publ. SUDENE: 1-47.

BEURLEN, K. - 1971 - As condições ecológicas e faciológicas da Formação Santana na Chapada do Araripe (Nordeste do Brasil). An. Acad. Bras. Ciênc. 43: 411-415 (Suplemento).

BRAUN, O.P.G. - 1966 - Estratigrafia dos sedimentos da parte inferior da região Nordeste do Brasil (Bacias de Tucano-Jatobá, Mirandiba e Araripe). Bol. D.N.P.M., Div. Geol. Miner. 236: $1-15$

COMISSÃO AMERICANA DE NOMENCLATURA ESTRATIGRÁFICA - 1963 - Código de Nomenclatura Estratigráfica. Publ. Inst. Geol. Univ. Recife. Ser. Didát. 1: 1-58. Tradução de J.C. Mendes.

HARRINGTON, H.J. e TURNER, J.C.M. - 1974 - Comentários al Codigo Norteamericano de Nomenclatura Estratigráfica. Actas 1. Congr. Arg. Paleont. Bioestrat. 2: 661-674.

LIMA, M.R. de - 1978a - Palinologia da Formação Santana (Cretáceo do Nordeste do Brasil). Univ. São Paulo. Tese de Doutoramento (inédita): 1-335, est. 1-27.

LIMA, M.R. de - 1978b - Microfósseis da Formação Exu, Cretáceo do Nordeste do Bra sil. An. XXX Cong. Bras. Geol. 2: 965-969.

MORAES, J.S. - 1976 - Relatório final da Etapa 1 - Projeto Santana. Comp. Pesq. Rec. Min.: 1: 1-261.

MORAES, L.J. de - 1928 - Estudos geológicos no Estado de Pernambuco, Brasil. Bol. Serv. Geol. Miner. Brasil, 32: 1-100.

SILVA SANTOS, R. da S. e VALENÇA, J.G. - 1968 - A Formação Santana e sua Paleoictiofauna. An. Acad. Bras. Ciênc. 40 (3): 339-360, 1 est.

SMALL, H.L. - 1913 - Geologia e suprimento de água subterrânea no Ceará e parte do Piauhy. Publ. Inspet. Obr. contra secas. 25: 1-80. 